\title{
La Mejor Arma que Usó Benjamín Herrera para Fomentar un Cambio en la Sociedad: la Educación
}

\author{
The Best Weapon Benjamin Herrera Used to Foster Change in Society: the Education \\ ${ }^{a}$ Gabriela Andrea Plata Mejía ${ }^{3}$, Iván Aycardi Coneo ${ }^{b}$ \\ a gabrielaplata04@gmail.com, Grupo de Investigación “Ciencia Libre”, Semillero de Investigación “Cultura sin Fronteras”, de la \\ Universidad Libre Sede Cartagena. Cartagena, Colombia. \\ b ivan20012015@gmail.com, Grupo de Investigación “Ciencia Libre”, Semillero de Investigación “Cultura sin Fronteras”, de la \\ Universidad Libre Sede Cartagena. Cartagena, Colombia.
}

\begin{abstract}
Forma de Citar: G. A. Plata - Mejía e I. Aycard i- Coneo "La mejor Arma que Usó Benjamín Herrera para Fomentar un Cambio en la Sociedad: La Educación”, Rev. Saberes, Vol. 13, No. 02, pp. 23 - 28, 2020.
\end{abstract}

Recibido: 24/03/2020 Evaluación: 28/05/2020 Aceptado:30/06/2020 DOI: https://doi.org/10.25213/1794-4384/1302.0003

\section{Resumen}

En el presente proyecto recuperaremos como pilar fundamental la memoria histórica de un personaje que ha sido olvidado por muchos ciudadanos, desconociendo el papel fundamental que ejerció en la cultura colombiana, rompiendo esquemas y paradigmas establecidos en una época crucial para Colombia donde transcurría una crisis que generó caos y sufrimiento, como la Guerra civil colombiana (1876- 1877), La guerra de los mil días, entre otras crisis.

El gran acontecimiento que se destaca y que es nuestra idea central, es cómo Benjamín Herrera, un militar y político con ideas de revolución en un tiempo que marcó a nuestro país por las vidas que se perdieron en esta lucha de ideas y de control político, buscó una solución, sin requerir de las armas, y que como muchos historiadores, filósofos, doctrinante y personajes importantes de la historia, como Nelson Mandela, quien sostenía que : " $L a$ educación es el arma más poderosa que puedes usar para cambiar ale mundo".

Benjamín Herrera utilizó esa ideología de cambio, creando un espacio de formación superior donde el pueblo pueda recibir una formación integral que ayude a construir una mejor sociedad. Es debido a este gran aporte que recalcamos la importancia de conocer este acto de revolución que puede servir de ejemplo para cambiar muchos aspectos de la sociedad, utilizando esta gran arma como lo es la educación, conllevando a que se pueda tener el reconocimiento y espacio en los órganos importantes para la legislación y justicia colombiana, en efecto, deberíamos apropiarnos de este gran ejemplo sobre todo la comunidad Unilibrista como signo de pertenencia.

\begin{abstract}
In this project we will recover as a fundamental pillar the historical memory of a character that has been forgotten by many citizens, ignoring the fundamental role he played in Colombian culture, breaking schemes and paradigms established in a crucial time for Colombia where a crisis that generated chaos and suffering, such as the Colombian Civil War (1876-1877), The war of a thousand days, among other crises.

The great event that stands out and that is our central idea, is how Benjamín Herrera, a military and politician with ideas of revolution in a time that marked our country for the lives that were lost in this struggle of ideas and
\end{abstract}

\footnotetext{
${ }^{3}$ Autor para correspondencia: correo electrónico: gabrielaplata04@gmail.com 
political control, He sought a solution, without requiring weapons, and like many historians, philosophers, doctrinants and important figures in history, such as Nelson Mandela, who argued that: "Education is the most powerful weapon you can use to change the world." .

Benjamín Herrera used this ideology of change, creating a space of superior formation where the people can receive an integral formation that helps to build a better society. It is due to this great contribution that we emphasize the importance of knowing this act of revolution that can serve as an example to change many aspects of society, using this great weapon such as education, leading to recognition and space in fact, the important bodies for Colombian legislation and justice, we should appropriate this great example, especially the Unilibrista community as a sign of belonging.

\section{Palabras Clave}

Educación Libre, Frente Nacional, humanista, Acuerdo 01 de 1986, cultura institucional, pensamiento Unilibrista.

\section{Keywords}

Free Education, National Front, Humanist, Agreement 01 of 1986, institutional culture, Unilibrista thought.

\section{Introducción}

El general Benjamín Herrera nació en Santiago de Cali el 24 de octubre de 1850 y murió en Bogotá el 29 de febrero de 1924, Estudiaba Jurisprudencia en la Universidad del Cauca, en Popayán, cuando estalló la guerra civil de $1876^{4}$. Herrera abandonó sus

\footnotetext{
${ }^{4}$ Conflicto interno de Colombia que tuvo un carácter políticoreligioso y fue la manifestación de los intereses del Partido Conservador Colombiano en oposición al gobierno de la facción radical del Partido Liberal Colombiano.

${ }^{5}$ conflicto que tuvo lugar en los Estados Unidos de Colombia (actuales naciones de Colombia y Panamá). Fue producto de la manifestación de los intereses del Partido Liberal, el cual no estaba de acuerdo con la política centralista de La Regeneración del presidente Rafael Núñez
}

estudios y se unió al ejército del Gobierno liberal del Estado Soberano del Cauca en contra de las fuerzas conservadoras.

Cuando estalló la guerra civil de $1885^{5}$. Herrera decidió abandonar el ejército del Gobierno y se afilió al bando radical, no participó en la guerra civil de 1895 porque había sido arrestado por sus ideas políticas.

Cuando salió de la cárcel tuvo que exiliarse, a su regreso participo en la Guerra de los mil días surgió porque los liberales querían llegar al poder para acabar los abusos de la regeneración ${ }^{6}$, la corrupción y la violencia del Gobierno en contra de la población civil que se le oponía pacíficamente, luego de esta guerra, Benjamín Herrera cedió su ejército a Rafael Uribe ${ }^{7}$, ingeniosamente logró escabullirse de las autoridades que lo buscaba y logró salir al extranjero a canalizar y traer recursos y armamento para revolución. (Castaño, 2017).

En 1886 se fundó la Universidad del externado de Derecho, pero su ideología estaba basada en un pensamiento conservador, pasado los años, en 1913, se dio la constitución de una Sociedad llamada Universidad Libre, como entidad independiente de la Republicana, plasmada en la escritura pública 1183 del 30 de octubre de 1913 de lo cual hablaremos de manera detallada a continuación.

\section{Justificación}

Esta ponencia de investigación se enfocará en estudiar la importancia que tiene este gran acontecimiento, de un personaje que ha sido ignorado por muchos $\mathrm{y}$ sobre todo por la misma comunidad unilibristas que de una a otra forma hacen parte de este proyecto, que hace muchos años nació de un gran hombre

\footnotetext{
${ }^{6}$ movimiento político surgido en Colombia en la segunda mitad del siglo XIX, liderado por Rafael Núñez. Su objetivo era cambiar la organización que tenía el gobierno y la sociedad colombiana, a partir de lo establecido por la Constitución de 1863, con la que habían creado los Estados Unidos de Colombia y que convirtió al país en una república federal, el lema de la regeneración fue "una nación, un lema, un Dios"

7 Rafael Víctor Zenón Uribe fue un abogado, periodista, diplomático y militar colombiano. Murió asesinado en las afueras del Capitolio Nacional.
} 
que a pesar de ser entrenado para la guerra, utilizó el arma más poderosa para derrotar el esquema que se establecía en esa época y generar un espíritu de revolución, incentivando la búsqueda de un conocimiento libre y autónomo, alejado de los paradigmas que se establecían por encima de todo.

Buscar la forma de expandir este conocimiento a la población y como prioridad a los líderes sociales, es conveniente porque se tomaría como ejemplo este gran símbolo de innovación y cambio como es la apertura de espacios académicos donde la sociedad pueda ser instruida para la creación de un pensamiento autónomo, libre y que contribuya a un cambio y como signo de pertenencia en la identidad Unilibrista, la apropiación de este conocimiento, valorando el contexto histórico de esta magna universidad que hoy conocemos.

\section{Objetivo General}

Proporcionar vías de aprendizaje de forma didáctica y flexible al conocimiento de los cuidados y comunidad Unilibrista, que ayuden a entender la importancia de la memoria histórica de este solemne personaje como lo es Benjamín Herrera, de esta forma reafirmar la importancia que tuvo en la creación de nuestra magna Universidad y el impacto que género en la sociedad.

\section{Objetivos Específicos}

- Crear espacios de aprendizaje en la Universidad Libre de Cartagena, empezando por reconocer y apreciar este gran contexto histórico generando un verdadero sentido de pertenencia

- Elaborar diferentes herramientas de información, actividades, dinámicas y de más métodos de aprendizaje, que ayuden a expandir este aprendizaje desde los trabajadores administrativos de la universidad en cabeza del rector y decanos hasta la comunidad estudiantil

- Difundir este conocimiento en las diferentes sedes de Colombia que posee la Universidad Libre de Cartagena, logrando como universidad multicampus, una formación integral de nuestra cultura unilibrista.

- Estructurar un sistema de publicidad visible, donde todos los interesados puedan tener acceso a esta información, incentivándolos a estudiar en nuestros planteles y seguir con el legado de Benjamín Herrera.

- Crear semilleros de investigación basados en la búsqueda de conocimiento y aplicación de las ideas de nuestro gran personaje.

\section{Origen de la Universidad Libre}

la historia de la Universidad Libre comienza en una época en la cual cuyo sistema educativo se orientaba sobre los principios de autoritarismo pedagógico, donde se tenía una gran influencia no sólo ideológica sino en su propia intimidad personal, así mismo, existía la universidad del externado, pero se tenía la intención de unirse a la prestigiosa universidad Republicana, sin embargo, esta entra en decadencia y no es posible que se logre este mencionado cambio, pero un grupo de aventajados tratan de rescatarla y fundaron una compañía anónima de capital limitado, que tendría como aporte principal la Universidad Republicana ya existente, la cual sería cedida por su propietario, el doctor Eugenio J. Gómez, a la sociedad que se iba a crear.

Años después, se logró una reforma constitucional que consagró el respeto a las garantías ciudadanas y se expidió la llamada Ley de Minorías inspirada en análogos propósitos, gracias a esto se conciben nuevos ideales y se empieza vislumbrar una nueva visión sobre la enseñanza libre y es posible avanzar sin temores hacia metas universales, científicas y técnicas.

Es por esto que grandes influyentes propugnan un cambio propugnan por la conversión de la Universidad Republicana en un Centro de ideas, artes y oficios, denominación que pone en evidencia un propósito de integración científico humanista, que no se logra exactamente, pero que da lugar, en 1913, a la constitución de una sociedad llamada Universidad Libre, como entidad independiente de la Republicana, plasmada en 
la escritura pública 1183 del 30 de octubre de 1913, de la Notaría Tercera del circuito de Bogotá, pero dicho proyecto no contaba con el número de acciones necesarias para el funcionamiento.

Herrera reunió al partido en la histórica convención del 29 de marzo de 1922, en Ibagué. Fue allí cuando el doctor Cesar Julio Rodríguez, gerente de la Universidad Libre, dirigió un conocido mensaje al general Benjamín Herrera y a la convención, exhortándolos una vez más a que tomarán decisiones eficaces que permitieran lograr un mejor funcionamiento de la Universidad.

La convención aprobó el Acuerdo 06, en donde recomienda a los liberales prestar un decidido apoyo a la obra de la fundación de la Universidad Libre. El general Herrera tomó personalmente la iniciativa de recaudar dineros para impulsar la apertura de la Universidad en forma definitiva. Fue elegido él como presidente del Consejo Directivo y desde esa posición, puso en marcha a la Universidad Libre. Estos años son de trascendencia para la educación liberal en Colombia. Al resurgimiento del Externado, en 1918, se agrega la iniciación de labores de la Universidad Libre en 1923. Es inexplicable que surgiera una tendencia integracionista de las dos instituciones, promovida por sus cabezas. El experimento académico no prospera y en 1923, se definen con claridad los propósitos finales de consolidar al Externado y a la Universidad Libre en sus propios principios doctrinarios y sus objetivos educacionales.

\section{Objetivos de la Universidad Libre}

1. Realizar investigación científica, técnica y tecnológica, en aquellos campos que demanden las zonas de influencia de la Corporación, para buscar soluciones teóricas y prácticas que contribuyan al desarrollo y al progreso de los sectores educativo, económico, social y político de los colombianos.

2. Adelantar programas de educación en diversas modalidades y niveles.
3. Fomentar la cultura, la investigación, la formación profesional, la prestación de servicios de asistencia y promoción social, orientados a elevar el desarrollo socioeconómico del país.

4. Propiciar la integración de la Corporación con otros sectores básicos de la actividad socio-económica, a nivel regional y nacional.

5. Realizar intercambios educativos, culturales, científicos, artísticos y de servicios con entidades nacionales y extranjeras que conduzcan a la defensa de los principios y al cumplimiento de los objetivos de la Corporación, dentro del contexto constitucional y legal colombiano.

6. Promover la formación científica y pedagógica del personal docente $\mathrm{e}$ investigativo, que garantice la calidad de la educación en sus diferentes niveles y modalidades.

7. Formar en el estudiante una conciencia crítica constructiva para el ejercicio de sus derechos y el cumplimiento de sus deberes, con fundamento en la función social de la educación.

8. Coadyuvar a la preservación de los recursos naturales.

9. Auspiciar la capacitación y la educación continuada tendientes a la formación integral de los colombianos.

10. Publicar periódicos, revistas, libros y folletos y editar videos y similares para divulgar las investigaciones, planes, programas y proyectos de la Corporación.

11. Buscar la formación de profesionales en todas las áreas del conocimiento, que sobresalgan por su entereza moral, excelencia académica, amor al estudio y a la investigación, decisión de luchar en defensa de la democracia, la libertad y la dignidad del hombre, y, por tanto, personas tolerantes, respetuosas de las creencias y derechos de los demás. (Acuerdo No. 01 de 1986, pág. art 2)

¿Cuáles son los principios de la Universidad Libre que defendía Benjamin Herrera?

La universidad se rige por los principios de las libertades de cátedra, examen y aprendizaje, de universalidad, pluralismo ideológico, moralidad, igualdad, fraternidad, democracia, 
excelencia académica y desarrollo sostenible. Principios que desde sus orígenes han sido los pilares fundamentales de esta institución forjando profesionales integrales, con las competencias esenciales para su desarrollo en la sociedad (Acuerdo No. 01 de 1986).

\section{Metodología}

En cuanto a la metodología de la ponencia, utilizamos un método histórico ya que está basado en el estudio de la trayectoria de los acontecimientos donde jugó un papel fundamental Benjamín herrera, como lo es impulso o apoyo que le brindó a esta gran iniciativa en un momento de crisis; el tipo de investigación utilizada es exploratoria ya que nuestro objetivo es examinar un problema de investigación poco estudiado.

La fuente utilizada es la secundaria en su génesis y primaria con posterioridad, cuando sea necesario la observación, entrevistas y encuestas. Por el momento nos apoyaremos en revistas, archivos y otros documentos, lo que hace esta propuesta bibliográfica.

\section{Discusión}

Benjamín, un hombre de admirar puesto que logró impulsar un sueño que aún sigue vigente, un sueño que en la actualidad ayuda y mantiene a muchas familias, desde el cargo más pequeño hasta el más alto, un sueño que ha logrado graduar estudiantes de la más alta calidad, estudiantes que han llegado a puestos importantes en el gobierno de nuestro amado país, grandes empresarios, médicos y demás profesiones, pero sobre todo, personas con principios y valores que en nuestra sociedad se han perdido, entonces ¿por qué no recordarlo con gratitud y afianzar ese legado?, fundado en lo anterior no hacemos la siguiente pregunta ¿Cómo podemos extender esta información de forma didáctica y flexible al conocimiento de los cuidados y generar un sentido de pertenencia y apropiación de la comunidad Unilibrista?

\section{Resultados}

1. Recuperación la memoria histórica de este gran personaje como lo fue Benjamín Herrera. 2. Elaboración de manera detalla los pensamientos e hipótesis de Benjamín herrera que nos ayuden a construir una sociedad mejor.

3. Concientización a los ciudadanos y, sobre todo, estudiantes de la universidad Libre, sobre el gran ejemplo que nos dejó este icono que utilizó la educación como arma, para combatir una época de crisis y sufrimiento que vivió Colombia.

4. Incentivación en la comunidad unilibrista de un sentimiento de pertenencia y amor hacia su institución, conociendo los orígenes de esta Magna Universidad.

5. Conocimiento de los pilares o principios que rigen esta Universidad y que han generado profesionales y personajes importantes para nuestra patria.

\section{Conclusión}

Como consecuencia de lo expuesto, podemos evidenciar que muchos no conocemos ni nos apersonamos de lo que debe tener un valor especial, por ser el principio de la historia que de una u otra forma influye en lo que hoy aprendemos, es por esto que queremos crear vías de aprendizaje de forma didáctica y flexible al conocimiento de los cuidados y comunidad Unilibrista, mostrándole a las personas que podemos generar cambios y por esta razón, debemos apropiarnos de este ejemplo a seguir y concientizarnos de que nuestros actos siempre tendrán consecuencias, las cuales son inexorables, y así como nuestro fundador se apropió de un proyecto, sin saber en lo grande y poderoso que se convertiría, podemos nosotros conocerlo más a fondo, inspirarnos y seguir su legado y que así como hoy, somos fruto de este pensamiento, podamos fortalecernos como árbol de tronco robusto y frondoso que se alimenta de nuestra Alma Mater, la universidad Libre. 


\section{Referencias Bibliográficas}

GUSTAVO HUMBERTO RODRIGUEZ, Presidente de la Corporación (), 27 de julio de 1994/ http://www.unilibre.edu.co/launiversidad/ul/historico-de-noticias/714acuerdo-no-01-de-1994 ALEJANDRO GARCÍA HERNÁNDEZ, 1 de Marzo de 2019

https://projusticiaydesarrollo.com/2019/03/01 /benjamin-herrera-el-estratega-que-logro-queel-liberalismo-llegara-al-poder/

"Benjamín Herrera". Revista Credencial Historia No. 179. noviembre de 2004. http://www.banrepcultural.org/bibliotecavirtual/credencial-historia/numero179/personajes-del-a\%C3\%B1o-1919-a-1921

Mejía, Jaime. "Los movimientos de proyectos educativos universitarios en un contexto histórico de la vida colombiana, en la construcción del Estado- Nación a finales del siglo XIX y comienzos del siglo XX". Escuela Superior de Administración Pública ESAP. Revista Polémica No. 9. 2008. https://issuu.com/esap/docs/polemica_ 9

5. Historia, Universidad Libre de Colombia, 20 junio de 2014 http://www.unilibrebaq.edu.co/unilibrebaq/in dex.php/historia 